\title{
Targeted Anticancer Strategies with Garlic Derivatives $^{+}$
}

\author{
Claudia Cerella ${ }^{1}$, Esma Yagdi Efe ${ }^{1}$, Mario Dicato ${ }^{1}$ and Marc Diederich 2,* \\ 1 Laboratoire de Biologie Moléculaire et Cellulaire du Cancer (LBMCC), Hôpital Kirchberg, \\ 9 Rue Edward Steichen, 2540 Luxemburg, Luxemburg; claudia.cerella@lbmcc.lu (C.C.); \\ esma.yagdi@lbmcc.lu (E.Y.E.); dicato.mario@chl.lu (M.D.) \\ 2 College of Pharmacy, Seoul National University, 1 Gwanak-ro, Gwanak-gu, Seoul 151-742, Korea \\ * Correspondence: marcdiederich@snu.ac.kr; Tel.: +82-2-880-8919 \\ + Presented at the Natural Products and the Hallmarks of Chronic Diseases-COST Action 16112, \\ Luxemburg, 25-27 March 2019.
}

Published: 19 April 2019

Keywords: Diallyl compounds; tubulin; Bcl-2; autophagic flux; apoptosis

Diallyl polysulfides from edible plants have been widely investigated in cancer research holding the promise of a translational application. Generally recognized as inducers of mitotic arrest and cell death, yet their activities appear broad, without specific intracellular targets. Here we suggest their potential as targeted agents and cancer types as suitable responders, taking the garlic-derived diallyl tetrasulfides (DATTS) and its most effective hemi-synthetic derivative di-benzyl tetrasulfide (DBTTS) as lead compounds [1-4]. We discovered DATTS/DBTTS as reversible tubulin binders, via redox modulation of the tubulin thiols. Translating our investigations to cellular models, we selected cancer types of the gastrointestinal tract (colorectal cancer, CRC) and the blood (acute forms of leukemia), being both highly proliferating and exposed in vivo to appropriate and stable concentrations of sulfur compounds. In both cell types, DATTS/DBTTS binding compromises the microtubule machinery, thereby inducing mitotic arrest and apoptosis [1-4]. Of note, a higher expression of genes coding specific tubulin isoforms in KRAS-mutated CRC SW480 and SW620 correlates with faster cell proliferation and the increased susceptibility to these compounds vs. the most resistant BRAFmutated HT-29 [1]. The resistance in HT-29 associated with the impairment of the autophagic flux concomitant with the prolonged mitotic block and characterized by 62 protein accumulation. Genetic p62 inhibition restores sensitivity. We confirmed the translational potential of DBTTS in 3D CRC models (in vitro: spheroids and colony formation assay; and in vivo: zebrafish xenografts) [1]. In both cell types, anti-apoptotic Bcl-2 protein members undergo phospho-modulation. In hematological cancer, Bcl-2 proteolysis/inhibition promotes cell death [2-4]. In line, Bcl-2 overexpression makes the cells more resistant; vice versa, isogenic cell lines expressing Bcl-2 mutated in the phosphorylable residues are again sensitized to the treatment, suggesting Bcl-2 proteins as critical stress sensors and transducers. Overall, we recommend components of the microtubule network, differential autophagic capacities, and Bcl-2 proteins modulation as essential factors of vulnerabilities to prioritize DATTS/DBTTS treatment.

Funding: C.C. and E.Y.E. were supported by a grant from Télévie Luxembourg. This research is supported by the "Recherche Cancer et Sang" foundation, "Recherches Scientifiques Luxembourg" association, "Een Häerz fir kriibskrank Kanner" association, Action LIONS "Vaincre le Cancer" association and Télévie Luxembourg. This research is also supported by National Research Foundation (NRF) [grant number 019R1A2C1009231] and by a grant from the MEST of Korea for Tumor Microenvironment Global Core Research Center (GCRC) [grant number 2011-0030001]. Support from Brain Korea (BK21) PLUS program and Creative-Pioneering Researchers Program at Seoul National University [Funding number: 370C-20160062] are acknowledged. This article is based 
upon work from COST Action NutRedOx-CA16112 supported by COST (European Cooperation in Science and Technology).

Conflicts of Interest: The authors declare no conflict of interest.

\section{References}

1. Yagdi Efe, E.; Mazumder, A.; Lee, J.Y.; Gaigneaux, A.; Radogna, F.; Nasim, M.J.; Christov, C.; Jacob, C.; Kim, K.W.; Dicato, M.; et al. Tubulin-binding anticancer polysulfides induce cell death via mitotic arrest and autophagic interference in colorectal cancer. Cancer Lett. 2017, 410, 139-157.

2. Kelkel, M.; Cerella, C.; Mack, F.; Schneider, T.; Jacob, C.; Schumacher, M.; Dicato, M.; Diederich, M. ROSindependent JNK activation and multisite phosphorylation of Bcl-2 link diallyl tetrasulfide-induced mitotic arrest to apoptosis. Carcinogenesis 2012, 33, 2162-2171.

3. Czepukojc, B.; Baltes, A.K.; Cerella, C.; Kelkel, M.; Viswanathan, U.M.; Salm, F.; Burkholz, T.; Schneider, C.; Dicato, M.; Montenarh, M.; et al. Synthetic polysulfane derivatives induce cell cycle arrest and apoptotic cell death in human hematopoietic cancer cells. Food Chem. Toxicol. 2014, 64, 249-257.

4. Cerella, C.; Scherer, C.; Cristofanon, S.; Henry, E.; Anwar, A.; Busch, C.; Montenarh, M.; Dicato, M.; Jacob, C.; Diederich, M. Cell cycle arrest in early mitosis and induction of caspase-dependent apoptosis in U937 cells by diallyltetrasulfide (A12S4). Apoptosis 2009, 14, 641-654.

(C) 2019 by the authors. Licensee MDPI, Basel, Switzerland. This article is an open access article distributed under the terms and conditions of the Creative Commons Attribution (CC BY) license (http://creativecommons.org/licenses/by/4.0/). 